\title{
Sistem Status Kelaikudaraan Pesawat Udara Berbasis Website Menggunakan Framework CodeIgniter dan PostgreSQL dengan Metode Prototype
}

\author{
Abdul Aziz ${ }^{1}$, Ildefonsa Anna Fransiska Nahak ${ }^{2}$, Irma Rismayanti ${ }^{3}$, Aries Asrianto Ramadian ${ }^{4}$, \\ Danartomo Kusumoaji ${ }^{5}$, Nurul Lailatul Muzayadah ${ }^{6}$, Rudi Choirul Anwar ${ }^{7}$ \\ 1,2,3,4,5,6,7 Pusat Teknologi Penerbangan, LAPAN, Jl. Raya LAPAN Rumpin Bogor, Indonesia, 16350 \\ e-mail: 1abdul.aziz@lapan.go.id
}

Submitted Date: October $23^{\text {rd }}, 2020$

Revised Date: December 30"th 2020
Reviewed Date: December $30^{\text {th }}, 2020$

Accepted Date: January $04^{\text {th }}, 2021$

\begin{abstract}
In aircraft operation, maintenance must always be carried out so that the aircraft meets airworthiness standards in order to meet flight safety, in which maintenance is carried out on aircraft components on a regular basis. The problem that exists today is that there is frequent damage to the aircraft without any known cause, even when the aircraft is flown which results in the plane crashing and experiencing severe damage until it can no longer be used. This condition is due to the absence of a system that can monitor the aircraft maintenance process, so that the components of the aircraft used to be flown cannot be known whether it is airworthy or not. The solution to overcome this problem is by building a website-based system. The system was built using the CodeIgniter framework and PostgreSQL as its database. Meanwhile, for system development using the Prototype method. Through this system the aircraft maintenance process can be carried out according to the existing schedule.
\end{abstract}

Keywords: CodeIgniter; PostgreSQL; Prototype; Airworthiness

\begin{abstract}
Abstrak
Dalam pengoperasian pesawat udara harus selalu dilakukan perawatan agar pesawat udara tersebut memenuhi standar kelaikudaraan guna memenuhi keselamatan penerbangan, yang mana perawatan dilakukan pada komponen-komponen pesawat secara berkala. Permasalahan yang ada saat ini yaitu sering terjadi kerusakan pada pesawat tanpa diketahui penyebabnya, bahkan kerusakan terjadi saat pesawat diterbangkan yang mengakibatkan pesawat tersebut jatuh dan mengalami kerusakan yang parah sampai tidak dapat dipakai lagi. Kondisi ini dikarenakan belum adanya sistem yang dapat memantau proses perawatan pesawat, sehingga komponen-komponen pesawat yang dipakai untuk diterbangkan tidak dapat diketahui apakah laik terbang atau tidak. Solusi untuk mengatasi permasalahan tersebut yaitu dengan membangun sistem berbasis website. Sistem yang dibangun menggunakan framework CodeIgniter dan PostgreSQL sebagai basis datanya. Sedangkan untuk pengembangan sistem menggunakan metode Prototype. Melalui sistem ini proses perawatan pesawat dapat dijalankan sesuai jadwal yang ada.
\end{abstract}

Keywords: CodeIgniter; PostgreSQL; Prototype; Kelaikudaraan

\section{Pendahuluan}

Pusat Teknologi Penerbangan merupakan satuan kerja LAPAN yang salah satu fokusnya yaitu melakukan penelitian dengan membuat pesawat udara khususnya pesawat udara tanpa awak. Pesawat udara yang telah dibuat harus selalu dilakukan perawatan agar pesawat udara tersebut memenuhi standar kelaikudaraan guna memenuhi keselamatan penerbangan. Keselamatan Penerbangan adalah suatu keadaan terpenuhinya persyaratan keselamatan dalam pemanfaatan wilayah udara, pesawat udara, bandar udara, navigasi penerbangan, serta fasilitas penunjang dan fasilitas umum lainnya (Poerwanto \& Mauidzoh, 2016). Perawatan dilakukan pada komponen-komponen yang ada pada pesawat secara berkala.

Kondisi yang ada saat ini, belum adanya sistem yang dapat memantau proses perawatan pesawat, sehingga komponen-komponen pesawat 
yang dipakai untuk diterbangkan tidak dapat diketahui apakah laik terbang atau tidak, karena tidak adanya perawatan secara berkala. Dengan adanya kondisi tersebut, sering terjadi permasalahan yang muncul yaitu kerusakan pesawat tanpa diketahui penyebabnya, bahkan kerusakan terjadi saat pesawat diterbangkan yang mengakibatkan pesawat tersebut jatuh dan mengalami kerusakan yang parah sampai tidak dapat dipakai lagi. Hal tersebut sangat berbahaya jika pesawat jatuh di pemukiman warga, yang memungkinkan dapat memakan korban.

Hal ini mengakibatkan perlunya ada sistem yang dapat menjadwalkan waktu perawatan secara dinamis, agar pesawat dapat diketahui kapan harus dilakukan perawatan maupun pergantian komponen sehingga pesawat dapat memenuhi standar kelaikudaraan. Dari pemikiran tersebut, penulis tertarik untuk membuat sistem status kelaikudaraan pesawat udara yang berbasis website. Website dapat diartikan sebagai kumpulan halaman yang menampilkan informasi data teks, data gambar, data animasi, suara, video dan gabungan dari semuanya, baik yang bersifat statis maupun dinamis yang membentuk satu rangkaian bangunan yang saling terkait, dimana masing-masing dihubungkan dengan jaringanjaringan halaman (Destiningrum \& Adrian, 2017).

Dalam pengembangan website ini, penulis menggunakan framework CodeIgniter karena pengerjaan website menjadi lebih cepat dibandingkan tanpa menggunakan framework. Framework memungkinkan kita membangun aplikasi dengan lebih cepat karena sebagai developer kita akan lebih memfokuskan pada pokok pemasalahan, sedangkan untuk hal-hal penunjang lainnya seperti koneksi ke database, form validation, GUI dan security umumnya telah disediakan oleh framework (Erinton, Negara, \& Sanjoyo, 2017). CodeIgniter menyediakan berbagai macam library yang dapat mempermudah dalam pengembangan dan termasuk framework tercepat dibandingkan dengan framework lainnya (Erinton, Negara, \& Sanjoyo, 2017).

Guna mengurangi resiko peretasan dan kebocoran data, penulis mengimplementasikan sistem ini pada server lokal yang hanya dapat diakses dari jaringan kantor saja, sehingga data tersimpan dengan aman. Seiring dengan kemajuan teknologi informasi maka sangat di perlukan sebuah keamanan data terhadap kerahasiaan informasi yang saling di pertukarkan melalui jaringan internet, apa lagi jika data tersebut dalam suatu jaringan komputer yang terhubung/terkoneksi dengan jaringan lain (Permana \& Nurnaningsih, 2018).

\section{Metode Penelitian}

\subsection{Metode}

Dalam metode pengembangan website, penulis menggunakan metode prototype. Penulis memilih metode prototype karena dalam proses pengembangan website ini melibatkan beberapa stackholder sehingga pengembang dan pelanggan bertemu dan mendefinisikan bersama keseluruhan sistem yang akan dibuat.

Prototype didefinisikan sebagai alat yang memberikan ide bagi pembuat maupun pemakai potensial tentang cara system berfungsi dalam bentuk lengkapnya, dan proses untuk menghasilkan sebuah prototype disebut prototyping (Fajarianto, 2016).

Untuk lebih lengkapnya metodologi penelitian berikut ini dapat dilihat pada Gambar 1 .

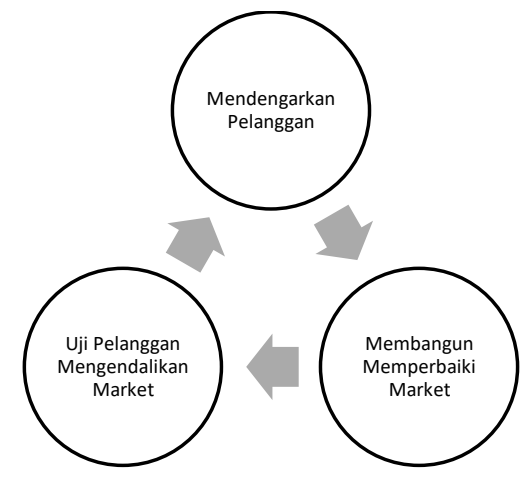

Gambar 1. Metode Prototype

Tahap yang pertama yaitu mendengarkan pelanggan. Pada tahap ini penulis dan tim operasi sebagai stackholder membahas bersama terkait gambaran sistem yang akan dibuat. Penulis mendifinisikan semua kebutuhan yang telah dibahas untuk diimplementasikan pada sistem.

Tahap yang kedua yaitu membangun memperbaiki market. Dalam membangun sistem status kelaikudaraan pesawat udara ini, penulis membangun sistem berbasis website/ web, web adalah sebuah software yang berfungsi untuk menampilkan dokumen-dokumen pada suatu web yang membuat pengguna dapat mengakses internet melalui software yang terkoneksi dengan internet (Destiningrum \& Adrian, 2017). Website ini dibangun menggunakan framework CodeIgniter, Framework adalah paket berisi fungsi-fungsi yang biasa digunakan dalam pembuatan aplikasi (Basuki, 2014). Untuk 
implementasi basis data penulis menggunakan PostgreSQL karena dapat menyimpan data yang banyak dan cepat. PostgreSQL atau sering disebut Postgres merupakan salah satu dari sejumlah basisdata besar yang menawarkan skalabilitas, keluwesan, dan kinerja yang tinggi. Penggunaannya begitu meluas di berbagai platform dan didukung oleh banyak bahasa pemrograman (Dhining, Rokhayati, \& Kurniawan, 2017).

Tahap yang ketiga yaitu uji pelanggan mengendalikan market. Proses pengujian dilakukan menggunakan pengujian black-box untuk mengetahui apakah sistem sudah berjalan dengan benar. Teknik pengujian black-box yang berfokus kepada proses input dan output untuk memeriksa apakah program tersebut sesuai dengan hasil yang diharapkan (Ningrum, Suherman, Aryanti, Prasetya, \& Saifudin, 2019). Tahap ini sistem diuji dengan studi kasus yang sudah dianalisis bersama-sama dengan tim operasi. Jika pada tahapan ini sistem belum sesuai dengan yang diinginkan, maka dapat dilakukan perbaikan website dengan kembali ke tahapan yang pertama.

\subsection{Analisis Sistem}

Analisis sistem dilakukan melalui proses identifikasi dan evaluasi masalah yang ada, kesempatan untuk solusi, hambatan yang akan terjadi juga kebutuhan yang diharapkan agar kemudian mengusulkan perbaikan-perbaikannya (Jogiyanto, 2017). Untuk mengetahui fungsi apa saja yang ada di dalam sebuah sistem dan siapa saja yang berhak menggunakan fungsi-fungsi tersebut, maka penulis menggambarkannya dalam Use case Diagram yang terlihat pada Gambar 2.

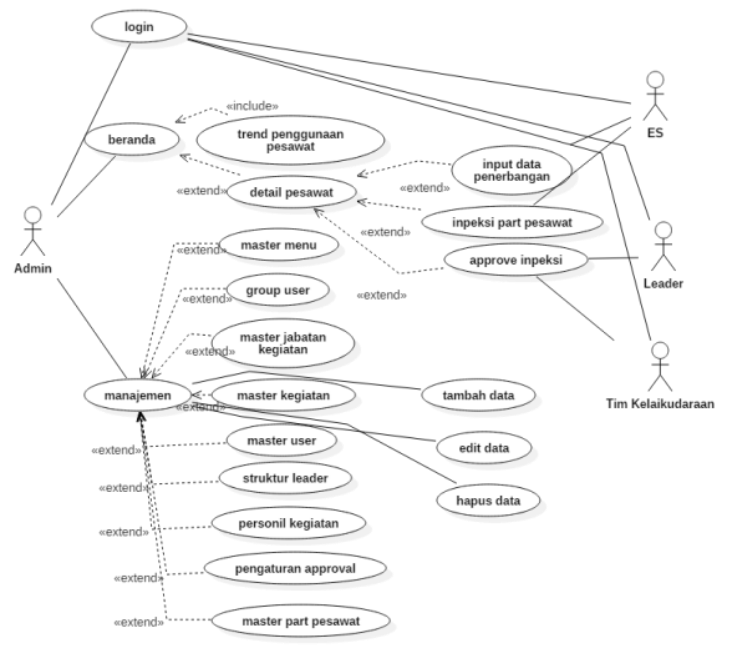

Gambar 2. Use Case Diagram Sistem
Pada use case menggambarkan kegiatan utama yang dilakukan oleh masing-masing aktor, agar mudah dimengerti terkait gambaran sistem status kelaikudaraan pesawat udara. Pada use case diagram terlihat ada 4 aktor yang berperan dalam pengoperasian website ini yaitu Admin, ES, Leader dan Tim Kelaikudaraan. Tiap aktor memiliki use case yang berbeda-beda maupun beririsan menyesuaikan arah panah seperti gambar di atas.

\section{Hasil Penelitian}

Integrasi bentuk prototipe merupakan tahap selanjutnya untuk pembuatan sistem status kelaikudaraan pesawat udara ini, tahap ini sebagai tahap saat suatu sistem sudah siap untuk diterapkan dengan keadaan sebenarnya. Sehingga dapat diperoleh informasi apabila sistem yang dirancang bangun sudah dapat menghasilkan tujuan yang tepat guna untuk menyelesaikan masalah penelitian (Kadir, 2017).

Berikut ini tabel untuk perangkat yang digunakan dalam integrasi prototipe.

Tabel 1. Rincian Kebutuhan Komputer

\begin{tabular}{|l|l|}
\hline \multicolumn{1}{|c|}{ Perangkat Keras } & \multicolumn{2}{|c|}{ Spesifikasi } \\
\hline Processor & Intel(R) Core(TM) i3- \\
& $6006 \mathrm{C} \quad$ CPU @ \\
& $2.00 \mathrm{GHz} 1.99 \mathrm{GHz}$ \\
\hline Hard Disk & $1 \mathrm{~TB}$ \\
\hline Memory RAM & $4 \mathrm{~GB}$ \\
\hline Monitor & 15.6 " (16:9) LED \\
& backlit HD \\
\hline Mouse & Standart \\
\hline Keyboard & Chiclet keyboard \\
\hline
\end{tabular}

Tabel 2. Rincian Perangkat Lunak (Software)

\begin{tabular}{|c|c|}
\hline Perangkat Lunak & Spesifikasi \\
\hline $\begin{array}{ll}\text { Sistem } & \text { Operasi } \\
\text { Komputer } & \\
\end{array}$ & Windows 10 Pro 64-bit \\
\hline Web Browser & Mozilla Firefox 78.0.2 \\
\hline $\begin{array}{l}\text { Aplikasi Perancangan } \\
\text { Antar Muka }\end{array}$ & $\begin{array}{ll}\text { Balsamiq } & \text { Mockups } \\
3.5 .15 & \end{array}$ \\
\hline Aplikasi Pemodelan & StartUML 2.8.1 \\
\hline Web Server & Apache/2.4.27 \\
\hline Code Editor & Notepad++ 7.5.1 \\
\hline Bahasa Pemrograman & PHP 7.1.9 \\
\hline Framework & CodeIgniter 3.1 .9 \\
\hline Database & PostgreSQL 9.5 \\
\hline
\end{tabular}

Dari hasil integrasi bentuk prototipe maka diperoleh antarmuka yang telah. Adapun bentuk utama hasil implementasi di antaranya antarmuka 
Status Kelaikudaraan, Informasi Umum Pesawat, Dokumen Laporan Status Kelaikudaraan, Daftar TSN (Time Since New) Pesawat, Daftar Inspeksi, Daftar Komponen Pesawat dan Daftar Sertifikasi Pesawat.

Setelah login ke sistem, user akan masuk ke halaman beranda yang di halaman tersebut terdapat status kelaikudaraan. Status kelaikudaraan ini menampilkan daftar pesawat yang ada beserta total jam terbang dan status kelaikudaraan pesawat tersebut. Dimana total jam terbang diambil dari total TSN pada Airframe, sedangkan untuk status kelaikudaraan ditentukan dari telah diselesaikannya seluruh jadwal inspeksi pada tabel Aircraft status dan Task Status.

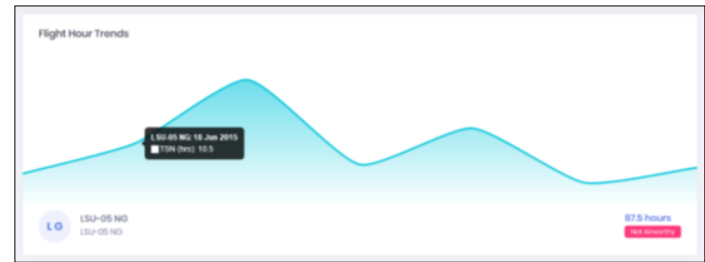

Gambar 3. Status Kelaikudaraan

Pada bagian nama pesawat terdapat link ke halaman detail pesawat, halaman detail ini merupakan halaman utama dalam memantau proses perawatan pesawat. Pada halaman ini terdapat informasi umum pesawat, mulai dari nama pesawat, posisi pesawat sampai detail airframe pesawat. Informasi umum ini berfungsi agar pengguna tahu pesawat yang sedang dilakukan perawatan.

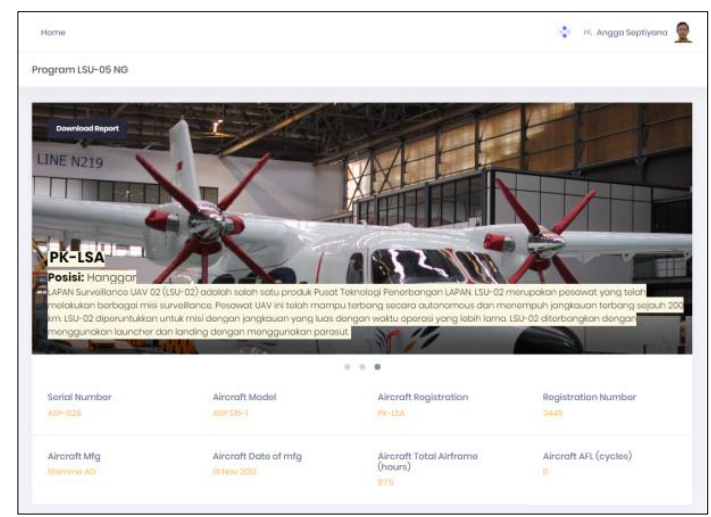

Gambar 4. Informasi Umum Pesawat

Pada bagian atas informasi umum pesawat terdapat link download report yang berfungsi untuk unduh dokumen laporan status kelaikudaraan. Dokumen ini menampilkan resume proses status kelaikudaraan pesawat udara yang dapat diunduh dalam bentuk file $p d f$.

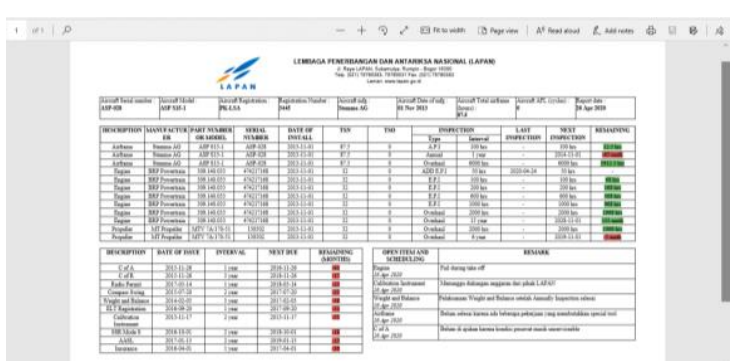

Gambar 5. Dokumen Laporan Status Kelaikudaraan

Pada halaman detail pesawat terdapat daftar TSN pesawat yang telah diinputkan oleh ES dan sedang menunggu persetujuan dari Leader dan Tim Kelaikudaraan. Ketika TSN pesawat tersebut telah selesai disetujui, maka TSN pesawat tersebut tidak akan ditampilkan lagi pada tabel tersebut.

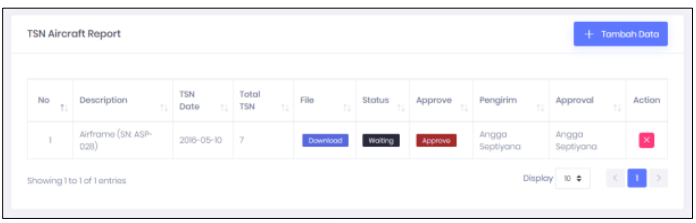

Gambar 6. Daftar TSN Pesawat

Selain Daftar TSN Pesawat, terdapat Daftar Inspeksi untuk perawatan pesawat yang telah dilakukan oleh ES dan sedang menunggu persetujuan dari Leader dan Tim Kelaikudaraan, dimana ketika inspeksi tersebut telah selesai disetujui maka inspeksi tersebut tidak akan ditampilkan lagi pada tabel tersebut.

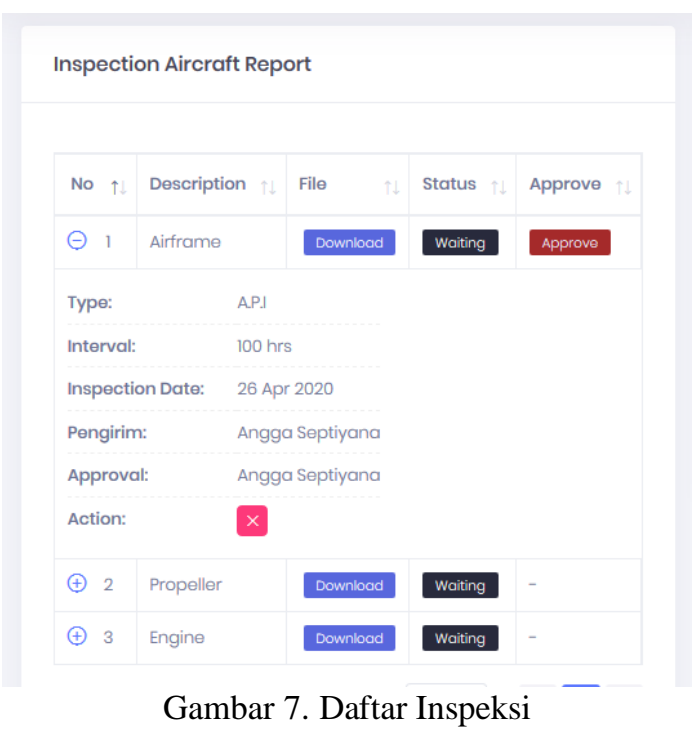

Selain Daftar Inspeksi, terdapat daftar komponen pesawat beserta jadwal inspeksi yang harus dilakukan pada masing-masing komponen. Pada tabel tersebut terdapat waktu interval yang 
diinputkan pada sistem dan sistem secara otomatis akan menghitung dengan waktu sekarang untuk menentukan kapan jadwal inspeksi harus dilakukan.

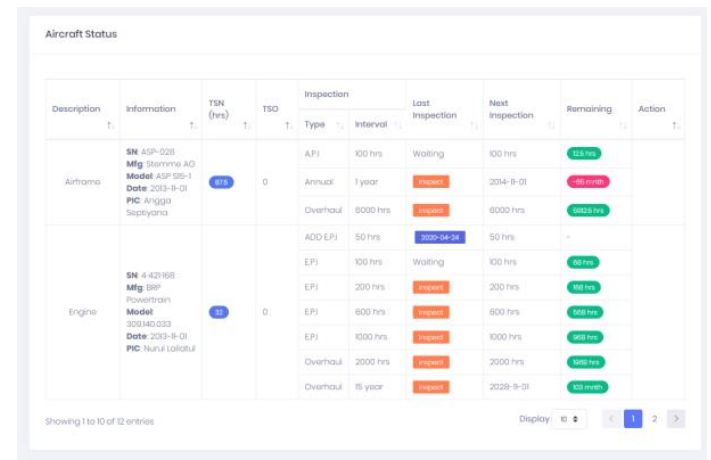

Gambar 8. Daftar Komponen Pesawat

Selain Daftar Komponen Pesawat, terdapat daftar sertifikasi pesawat beserta jadwal inspeksi yang harus dilakukan pada masing-masing sertifikasi pesawat. Pada tabel tersebut terdapat waktu interval yang diinputkan pada sistem dan sistem secara otomatis akan menghitung dengan waktu sekarang untuk menentukan kapan jadwal inspeksi harus dilakukan.

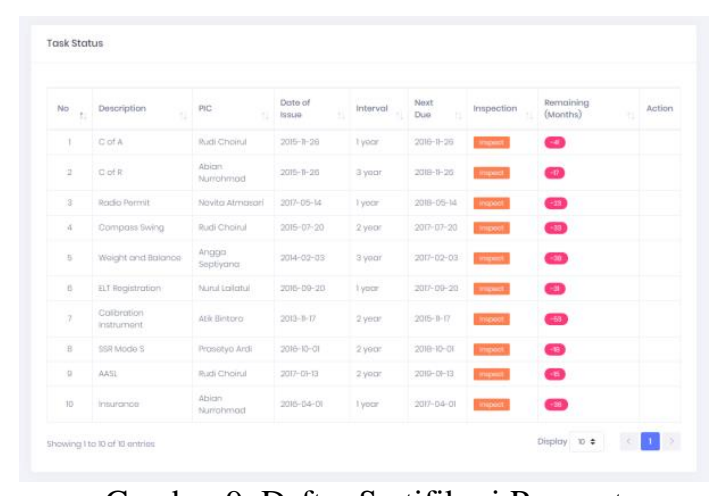

Gambar 9. Daftar Sertifikasi Pesawat

\section{Kesimpulan}

Penulis mencoba simpulkan bahwa sistem yang dibangun berdasarkan fungsi sesuai dengan yang diharapkan. Sehingga dalam memantau proses perawatan pesawat berjalan dengan baik. Salah satu pengujian yang dilakukan sebagai berikut.

Tabel 2. Pengujian dengan black-box

\begin{tabular}{|c|c|}
\hline $\begin{array}{l}\text { Data } \\
\text { Masukan }\end{array}$ & $\begin{array}{l}\text { Nama Dokumen: Format } \\
\text { Klik link download report }\end{array}$ \\
\hline $\begin{array}{l}\text { yan } \\
\text { apkan }\end{array}$ & \begin{tabular}{|lr} 
Sistem dapat & melakukan \\
pengunduhan & berupa \\
dokumen laporan & status \\
kelaikudaraan & dalam
\end{tabular} \\
\hline
\end{tabular}

\begin{tabular}{|l|l|}
\hline Pengamatan & $\begin{array}{l}\text { bentuk pdf } \\
\text { Dokumen laporan status } \\
\text { kelaikudaraan berhasil } \\
\text { diunduh dan menampilkan } \\
\text { data yang sesuai }\end{array}$ \\
\hline Status & Valid \\
\hline
\end{tabular}

Berdasarkan analisis SWOT, penulis mencoba simpulkan bahwa sistem yang dibangun memiliki banyak kelebihan dibandingkan sebelum adanya sistem ini dibuat, karena lebih banyak kekuatan pada sistem yang telah dibangun.

Analisis SWOT meliputi faktor internal kekuatan (Strenghts) dan kelemahan (Weaknesess) serta faktor eksternal yaitu peluang (Opportunity) dan ancaman (Treats) yang terdapat pada sistem status kelaikudaraan pesawat udara ini. Kekuatan yang ada pada sistem ini yaitu dapat mengetahui apakah pesawat laik terbang atau tidak, dapat mengetahui jadwal perawatan pesawat dan dengan adanya sistem ini perawatan pesawat dapat dilakukan secara berkala. Sedangkan untuk kelemahannya yaitu sistem hanya dapat diakses oleh jaringan kantor. Adapun peluang yang didapatkan yaitu sistem ini masih dalam proses pengembangan, sehingga masih banyak fitur yang dapat ditambahkan pada sistem ini, agar proses perawatan pesawat menjadi lebih baik. Dan ancaman yang dapat terjadi yaitu jika terjadi masalah pada server yang digunakan yang mengakibatkan sistem tidak dapat diakses dan proses perawatan dapat terganggu, namun hal ini dapat dilakukan pencegahan dengan melakukan backup server.

\section{Saran}

Penulis mengharapkan penelitian ini dapat bermanfaat, untuk selanjutnya dapat dikembangkan dan ditambahkan fitur-fitur lainnya sehingga menjadi penelitian berkelanjutan. Kebutuhan dalam proses perawatan pesawat udara akan selalu berkembang sehingga akan banyak pengembangan dari penelitian yang sudah dilakukan.

Saran untuk pengembangan selanjutnya, sistem ini diharapkan dapat dikembangkan sesuai kebutuhan dari stackholder, agar proses perawatan pesawat dapat semakin berpengaruh terhadap kelaikudaraan pesawat udara.

\section{Referensi}

Basuki, A. P. (2014). Proyek Membangun Website Berbasis PHP dengan Codeigniter. Yogyakarta: Lokomedia. 
Destiningrum, M., \& Adrian, Q. J. (2017). Sistem Informasi Penjadwalan Dokter Berbassis Web dengan Menggunakan Framework Codeigniter (Studi Kasus: Rumah Sakit Yukum Medical Centre). Jurnal TEKNOINFO, 11(2), 30-37.

Dhining, D., Rokhayati, Y., \& Kurniawan, D. E. (2017). Penerapan Replikasi Data pada Aplikasi Ticketing Menggunakan Slony PostgreSQL. Journal of Applied Informatics and Computing (JAIC), 1(1), 9-18.

Erinton, R., Negara, R. M., \& Sanjoyo, D. D. (2017). Analisis Performasi Framework Codeigniter dan Laravel Menggunakan Web Server Apache. eProceeding of Engineering, 3565-3572.

Fajarianto, O. (2016). Prototype Pelayanan Akademik Terhadap Komplain Mahasiswa Berbasis Mobile. JURNAL LENTERA ICT, 3(1), 54-60.

Jogiyanto, H. (2017). Analisis dan Desain (Sistem Informasi Pendekatan Terstruktur Teori dan Praktek Aplikasi Bisnis). Yogyakarta: Andi.
Kadir, A. (2017). Pengenalan sistem informasi edisi revisi. Yogyakarta: Andi.

Ningrum, F., Suherman, D., Aryanti, S., Prasetya, H., \& Saifudin, A. (2019). Pengujian Black Box pada Aplikasi Sistem Seleksi Sales Terbaik Menggunakan Teknik Equivalence Partitions. Jurnal Informatika Universitas Pamulang, 125.

Permana, A. A., \& Nurnaningsih, D. (2018). Rancangan Aplikasi Pengamanan Data dengan Algoritma Advanced Encyption Standard (AES). JURNAL TEKNIK INFORMATIKA, 11(2), 177-186.

Poerwanto, E., \& Mauidzoh, U. (2016). Analisis Kecelakaan Penerbangan di Indonesia Untuk Peningkatan Keselamatan Penerbangan. JURNAL ANGKASA, 8(2), 9-26. 